This item was submitted to Loughborough's Research Repository by the author.

Items in Figshare are protected by copyright, with all rights reserved, unless otherwise indicated.

\title{
Lithographically printed voltaic cells - a feasibility study
}

PLEASE CITE THE PUBLISHED VERSION

http://dx.doi.org/10.1108/03056120710723698

PUBLISHER

(C) Emerald

VERSION

AM (Accepted Manuscript)

LICENCE

CC BY-NC-ND 4.0

REPOSITORY RECORD

Southee, Darren J., Gareth I. Hay, Peter S.A. Evans, and David J. Harrison. 2019. "Lithographically Printed Voltaic Cells - a Feasibility Study". figshare. https://hdl.handle.net/2134/8473. 
This item was submitted to Loughborough's Institutional Repository (https://dspace.lboro.ac.uk/) by the author and is made available under the following Creative Commons Licence conditions.

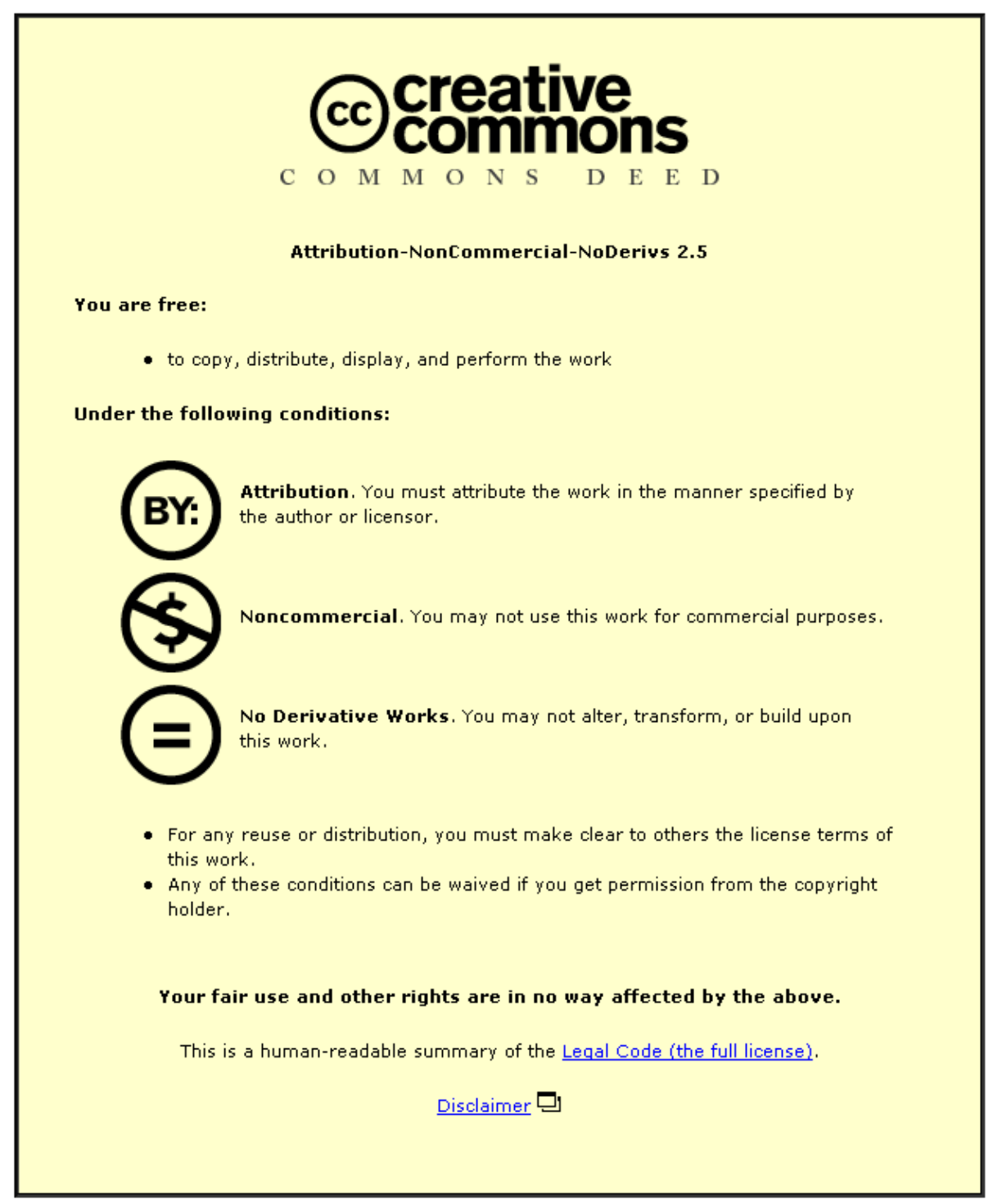

For the full text of this licence, please go to: http://creativecommons.org/licenses/by-nc-nd/2.5/ 
This article is a version after peer-review, with revisions having been made. In terms of appearance only this might not be the same as the published article.

\title{
Lithographically Printed Voltaic Cells - A Feasibility Study
}

\author{
Darren Southee*, Gareth I. Hay, Peter S. A. Evans and David J. Harrison \\ Cleaner Electronics Research Group \\ School of Engineering and Design \\ Brunel University \\ Uxbridge, Middlesex, UB8 3PH, U.K. \\ * Darren.Southee@brunel.ac.uk, +44 (0) 1895274000
}

Journal: Circuit World, ISSN: 0305-6120, Year: 2007 Volume: 33 Issue: 1 Page: 31 - 35

DOI: $10.1108 / 03056120710723698$

Publisher: Emerald Group Publishing Limited

\begin{abstract}
Purpose - It has been shown that circuit interconnect and various passive components can be fabricated on a variety of flexible substrates using the offset lithographic process. This paper reports on a feasibility study investigating the manufacture of voltaic cells deposited via offset lithography.

Design/methodology/approach - The Leclanché cell, an established battery chemistry, was chosen as an appropriate technology for adaptation to the offset lithographic process. Development of inks with appropriate rheological properties for lithographic printing was undertaken. Zinc and Carbon electrodes were fabricated with silver-based current collectors. Electrolyte composition was investigated along with separator materials.
\end{abstract}

Findings - Zinc and Carbon-based inks have been produced which result in deposited material appropriate for use as electrodes. A separator material soaked in electrolyte has been combined with these electrode structures and an $\mathrm{MnO}_{2}$ paste to form a voltaic cell. A printed battery, made up of these voltaic cells, with a capacity greater than $8 \mathrm{mAh}$ at $6 \mathrm{v}$ has been produced

Originality/value - The fabrication of voltaic cells via offset lithography facilitates the production of electronic systems with power sources provided by the same printing process. This paper provides information of interest to all those involved in the developing industry of printed and flexible electronics.

Keywords - Conductive inks, Printed electronics, Offset lithography, CLF, Voltaic cells

Classification - Research paper

\section{Introduction}

There are numerous environmental problems associated with photo- resist and etching processes used in conventional "printed" wiring board manufacture. These include:

- Spent etching solutions that are environmental pollutants and incur extra costs in disposal;

- Complex multiple processes are required;

- Toxic materials and waste-products;

- Conventional wiring boards contain lead $(\mathrm{Pb})$ and various fire retardants and fungicides. End of life disposal is therefore environmentally problematic.
The Conductive Lithographic Film (CLF) process was originally developed as an alternative for etched resin-laminate circuit boards. The technique utilises standard offset lithographic printing technology used in the mass production of books and magazines. The CLF process possesses a number of key advantages over more traditional forms of electronic circuit board fabrication:

- High production speed $(6,000-10,000$ impressions/hour)

- Good resolution of image (80 - 100 micron track with 60 micron gap achievable)

- Low cost (low ink volume determining that substrate material proves the largest expense) 
This article is a version after peer-review, with revisions having been made. In terms of appearance only this might not be the same as the published article.

- Ability to produce flexible electronic circuits and systems

- Reduced environmental impact (less energy, reduction in material use, easier disposal, toxic heavy metals (e.g. lead) eliminated)

Electrically conductive ink films can be printed on a wide range of flexible substrates including paper and polymer films. A range of passive components and sensor structures have been manufactured by the CLF process by designing structures that exploit the electrical properties of the printed ink films.

In the past few years trends towards greater integration in electronics, combined with reductions in power requirements, and demand for mobility, have led to increasing interest in using additive printing technologies for the production of electronics. The printing of RFID structures, using a variety of printing techniques, has received much attention [1]. Another development is the printing of batteries, using silk-screen technologies to produce zinc anode and manganese dioxide cathode layers fabricated from ink-like materials [2]. Developments in thin-film battery technology have been reported by 'Power Paper' - an Israeli company who have Patented processes for screen-printing various types of thick-film voltaic cell [3] [4]. Previous research conducted by our group has however established that screen-printed electronic components are both slower to manufacture and significantly more expensive than similar components fabricated by offset lithography. A key feature of the Power Paper screen-printed battery process is a deliquescent electrolyte that attracts sufficient water from the atmosphere to compensate for evaporation losses. Voltaic cells fabricated by the Power Paper process cannot therefore be sealed against leakage or external contamination.

The work has used Leclanché battery chemistry as the base from which lithographically printed voltaic cell electrodes could be formed. The zinc manganese (IV) dioxide Leclanché cell is one of the oldest forms of battery chemistry available. Many variations on the formulation of such cells exist yet much of the details are proprietary to the individual companies involved in their fabrication. However, Leclanché cells are a proven technology and are capable of developing up to $1.7 \mathrm{~V}$ with reasonable capacity for general domestic products [5].

The paper describes cell configurations and manufacturing processes while also presenting results demonstrating the performance of cells.
These results are discussed and suggestions for improvements in the manufacturing process are proposed.

\section{Discussion 1 Electrode Ink Development}

For a printable CLF ink the formulation must:

- be thixotropic (non-newtonian properties);

- be hydrophobic;

- remain fluid on press but dry quickly when deposited on substrate.

Lithographic printing inks are generally composed from two phases. The first, a colour pigment, takes the form of fine particulates and the second, an ink vehicle, acts as a carrier for the pigmentation through the printing press and provides a bonding mechanism for the pigmentation to the substrate material. Lithographically printable electronic inks developed by Brunel University are similar in composition to commercially available colour inks, such that, formulations are composed from an active 'electronic' material in particulate form (approximately $1-3 \mu \mathrm{m}$ in size) dispersed in an organic resin vehicle.

The ink fabrication process follows closely that of standard lithographic inks and includes;

- Polymeric ink vehicle mixed

- Conductive particulate introduced

- Three roll milling

- Fineness of grind dispersion tested

- Assessment of rheological properties

The polymer based vehicle portion of the ink consists of three components; a polymeric resin, which constitutes the largest portion of the vehicle, a non - volatile dilitant solvent to adjust the viscosity and an anti oxidant agent to retard drying of the ink during printing.

Each component of the ink is combined and agitated until a smooth uniform mixture is formed. To improve distribution of particulates and break down agglomerates the mixture is sheared on a three-roll mill. Without the process of milling it is likely agglomerates of active material will exist, thus reducing the likelihood of the ink attaining the correct rheological properties while also introducing uncertainties to the electrical characteristics of the cured ink film. Breaking down of the agglomerates causes an increase in particulate surface area which, 
This article is a version after peer-review, with revisions having been made. In terms of appearance only this might not be the same as the published article.

in turn, leads to a larger spread of vehicle over the surface of the active material, causing an increase in viscosity.

To obtain the degree of particulate dispersion and ensure no agglomerates of particulates are present, ink formulations are subjected to Fineness Of Grind testing (FOG test) using a grindometer. A grindometer is a precision fabricated block of stainless steel with two graduated troughs milled into the top surface. The troughs, running along the length of the block, have a start depth of $25 \mathrm{~mm}$ which graduate to $0 \mathrm{~mm}$ as they reach the opposite end of the block. FOG testing is conducted by depositing two beads of ink in either trough at the deepest end and drawing them down the grindometer using a flat edge or blade. The presence of agglomerates is apparent should "streaking" be observed in the drawn samples. The location of the streaks along the grindometer gives an indication of agglomerate size.

Ink rheological characteristics are obtained using a cone and plate type viscometer, model Haake VT550. It is important that lithographic printing inks attain the property of thixotropy (shear thinning).

Ink specimens are subjected to shear rates from $0 \mathrm{~s}^{-1}-400 \mathrm{~s}^{-1}$. During testing, measurements of shear stress are recorded and used to calculate the viscosity by the rule:

$$
\eta=\frac{\tau}{\gamma}
$$

where $\eta$ denotes viscosity (Pascalsecond, Pas), $\tau$ denotes shear stress $(\mathrm{Pa})$ and $\gamma$ denotes shear rate $\left(\mathrm{sec}^{-1}\right)$. Ink running through the ink train of a lithographic printing press is likely to be subjected to shear rates in the region of $10,000 \mathrm{~s}^{-1}$, however, in test conditions these shear rates are difficult to reproduce. It is widely accepted that if an ink achieves a viscosity in the region of $7-12$ Pas at $400 \mathrm{~s}^{-1}$, while exhibiting thixotropic behaviour, it is likely to perform well at increased shear rates.

Through a process of ink development, anode and cathode inks based on zinc and graphite particulates respectively were fabricated. The ink formulations utilise active materials with mean particulate distributions of approximately $3 \mu \mathrm{m}$. Composition of each formulation is detailed in Table 1 .

\section{Discussion 2 First iteration structure design}

Initial voltaic cells were fabricated by depositing suitable electrode structures using anode and cathode ink formulations. These structures utilising zinc - carbon chemistry were developed to prove that lithographically deposited electrode structures exhibit an electrochemical potential.

Electrode structures were orientated as depicted in Figure 1, such that cells comprised; substrate, cathode layer, electrolyte saturated membrane separator, anode layer, substrate.

The electrolyte mixture was formed by dispersing a small quantity of polyethylene oxide in water followed by the introduction of ammonium chloride. A small quantity of manganese dioxide, in fine particulate form, was introduced to the formulation to act as a depolarising element.

\begin{tabular}{rcc}
\hline \multicolumn{1}{c}{ Component } & Zinc ink & Graphite ink \\
\hline Mean particulate size: & $3 \mu \mathrm{m}$ & $3 \mu \mathrm{m}$ \\
Particulate (w/w): & $75 \%$ & $33 \%$ \\
XV1578 resin (w/w): & $90 \%$ & $77 \%$ \\
M71A solvent (w/w): & $9 \%$ & $22 \%$ \\
Eugenol anti-oxidant (w/w): & $1 \%$ & $1 \%$ \\
\hline
\end{tabular}

Both inks displayed shear thinning and viscosity values in the region of $7-9$ Pas at a shear rate of $400 \mathrm{sec}^{-1}$

Table 1. Anode and Cathode ink formulation

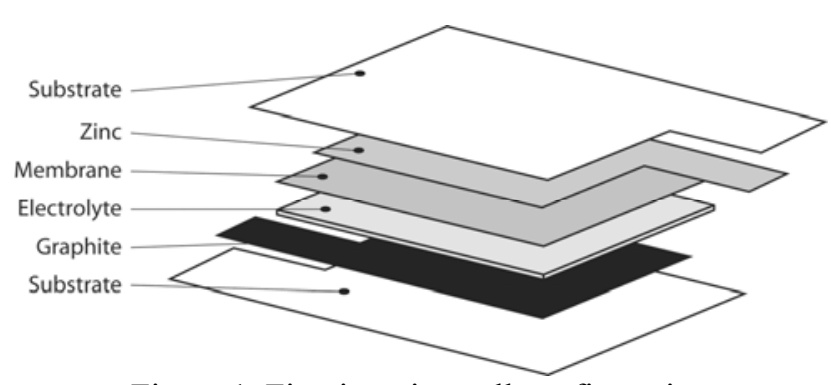

Figure 1. First iteration cell configuration

The principal operation of the membrane separator is to contain the electrolyte preventing migration of this phase through the cell. Cells were sealed using adhesive treated polymer film.

Discharge testing of these initial structures proved that an output greater than 1 volt was achievable, however, the current capability of such devices was poor. A peak short circuit current in the region of $2 \mathrm{nA}$ was recorded and has been attributed to the high sheet resistance of the graphite and zinc electrode structures (approximately $1.5 \mathrm{k} \Omega /$ and 2M $\Omega /$ respectively). 
This article is a version after peer-review, with revisions having been made. In terms of appearance only this might not be the same as the published article.

\section{Discussion 2 Second iteration structure design}

The configuration of second generation cells, Figure 2, followed closely that of initial cells, with key differences to electrode structures and the addition of a manganese (IV) dioxide paste. Graphite cathode and zinc anode structures were deposited on top of lithographically printed current collectors formed using a silver loaded conductive ink. Introduction of the current collectors reduces anode and cathode sheet resistivity to approximately $10 \Omega /$, resulting in reduced cell internal resistance.

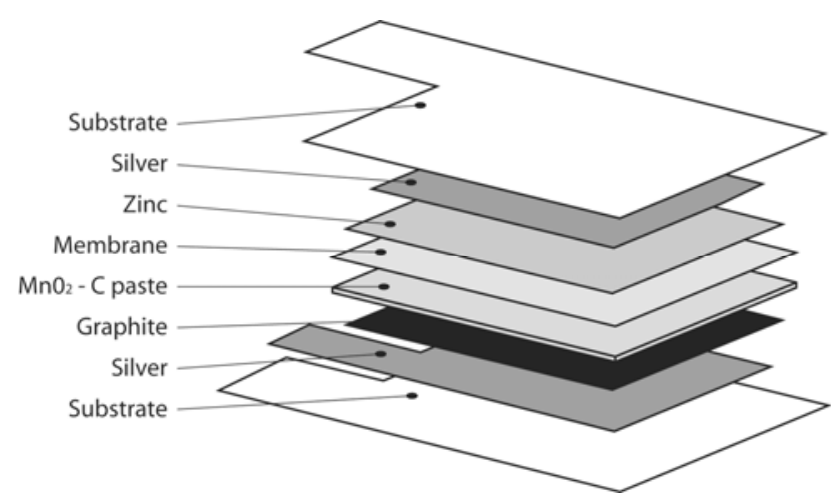

Figure 2. Second iteration cell configuration

Ink films deposited by offset lithography have a thickness of approximately $3-5 \mu \mathrm{m}$, which is in stark contrast to films deposited by screen printing processes (approximately $50 \mu \mathrm{m}$ ) and the thickness of foil material laminated to conventional resin laminate circuit boards (approximately $30-75 \mu \mathrm{m}$ ).

Capacity of a voltaic cell is proportional to the volume of anode and cathode material available for the electrochemical reaction. During discharge of a Leclanché cell, reduction of Manganese dioxide is the cathodic reaction and oxidation of zinc is the corresponding anodic reaction. The approximate half-cell reactions can be expressed as:

Anode:

$$
\mathrm{Zn} \rightarrow \mathrm{Zn}^{2+}+2 \mathrm{e}^{-}
$$

Cathode:

$$
2 \mathrm{NH}^{4+}+2 \mathrm{MnO}_{2}+2 \mathrm{e}^{-} \rightarrow \mathrm{Mn}_{2} \mathrm{O}_{3}+\mathrm{H}_{2} \mathrm{O}+2 \mathrm{NH}_{3}
$$

Considering the thickness of lithographically deposited films, cell development has focused on the formulation of a 'stencil' deposited manganese (IV) dioxide paste.

As in conventional Leclanché cell design, $\mathrm{MnO}_{2}$ pastes consist predominantly of manganese (IV) dioxide in particulate form mixed with water. In addition to this, carbon/graphite particulates are introduced to the formulation. The addition of graphite to the cathodic paste is important for two reasons. 1. The bulk resistivity of manganese (IV) dioxide is much higher than that of zinc (approximately $1.44 \mu \Omega m$ and $50 \quad \mathrm{n} \Omega \mathrm{m}$ respectively), hence carbon/graphite is required to reduce the bulk resistivity of the mixture. 2 . Whilst manganese (IV) dioxide is an important element in the electrochemical reaction, it also behaves as a depolarising element, converting hydrogen dissolved in the electrolyte solution (produced by oxidation of the anode material) into water. High concentration of aqueous hydrogen in the electrolyte causes hydrogen bubbles to form, resulting in increased cell internal resistance, hence deteriorating performance. The carbon / graphite portion of the cathodic paste acts as a transport mechanism promoting the ingress of hydrogen in solution into the manganese (IV) paste, hence increasing the surface area of $\mathrm{MnO}_{2}$ participating in the depolarising reaction.

A cathodic paste constituting a 75:25 ratio of $\mathrm{MnO}_{2}$ and $\mathrm{C}$ respectively was developed and is detailed in Table 2. During cell fabrication, a cathodic paste layer of approximately $300 \mu \mathrm{m}$ thickness was 'stencilled' over the graphite electrode structure. A paper membrane separator (approximately $500 \mu \mathrm{m}$ thick) saturated with the ammonium chloride electrolyte solution, detailed in Table 2, was positioned over the paste. Finally, the zinc anode was placed above the membrane completing cell fabrication, as detailed in Figure 2.

\begin{tabular}{rrr}
\hline \hline $\begin{array}{c}\text { Manganese (IV) dioxide } \\
\text { paste formulation }\end{array}$ & Electrolyte Composition \\
\hline $\mathrm{MnO}_{2}:$ & $42.9 \%$ & $\mathrm{NH}_{4} \mathrm{Cl}: \quad 25 \%$ \\
$\mathrm{C}:$ & $14.2 \%$ & Water: $\quad 75 \%$ \\
Water: & $42.9 \%$ & \\
\hline \hline
\end{tabular}

Table 2. Electrolyte and $\mathrm{MnO}_{2}$ paste composition

Second iteration structures were evaluated via constant discharge through a $5 \mathrm{k} \Omega$ load for 105 minutes. A typical discharge curve produced during evaluation is depicted in Figure 3.

Figure 3 suggests that discharge characteristics of lithographically deposited voltaic cells are not dissimilar to that expected from conventional Leclanché cell technology. Cell voltage is noticed to fall off at an increased rate during the first 80 minutes of discharge, after which, the rate of voltage drop decreases. 
This article is a version after peer-review, with revisions having been made. In terms of appearance only this might not be the same as the published article.

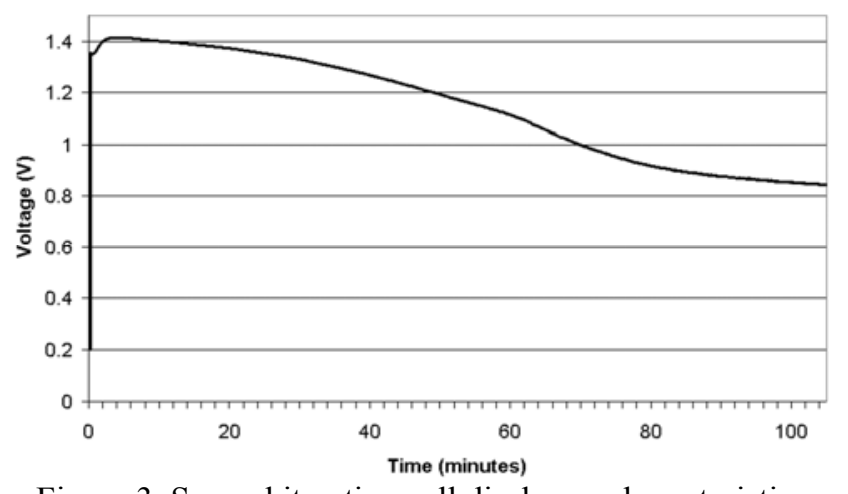

Figure 3. Second iteration cell discharge characteristics (300uA)

An output close to the expected cell potential of 1.5 $-1.7 \mathrm{~V}$ is obtained from the second iteration cell design.

Analysis has proven that the shelf life of second iteration cells is poor. Under no load, cell potential falls below $80 \%$ of maximum within 3 hours. One hypothesis to explain this characteristic concerns the substrate material employed for electrode fabrication. Teslin is a polyethylene based material designed for the printing industry, and is favoured for its high quality graphic reproduction, due predominantly to the surface composition. During manufacture, the extruded polyethylene is impregnated with silica to create a highly porous sheet. As such, approximately $60 \%$ of the materials volume is air. While aiding ink adhesion, due to absorption of the ink vehicle into the substrate surface, it is believed that the electrolyte phase of cells permeates the material and is drawn away from the cathodic and anodic materials, hence reducing cell capacity.

\section{Conclusions}

This paper describes a process of using offset lithographic printing to form electrode structures suitable for voltaic cell fabrication. Anode and cathode inks have been developed using active material in a particulate form suspended in a polymeric resin. Inks developed attain hydrophobic and thixotropic properties necessary to facilitate lithographic printing.

First iteration cells proved that suitable electrode materials could be printed and realised the chemical potential of Leclanché chemistry. Second iteration structures utilising silver current collectors achieved superior current capability compared to their predecessors.

Second iteration cell structures have been combined in a battery to power a microcontoller circuit incorporating an LED array, with an average current consumption $\sim 4 \mathrm{~mA}$, for over 3 hours, Figure 4.

\section{Future work}

It has been shown that the Conductive Lithographic Film printing process can be used to form electrode structures suitable for voltaic cell fabrication. It is proposed that the short shelf life of such cells is due to electrolyte absorption of the substrate material. Current work is concerned with the deposition of electrode structures on non porous PET substrate materials. The successful utilisation of such materials should extend cell shelf life by preventing electrolyte migration away from the electrochemically reactive materials.

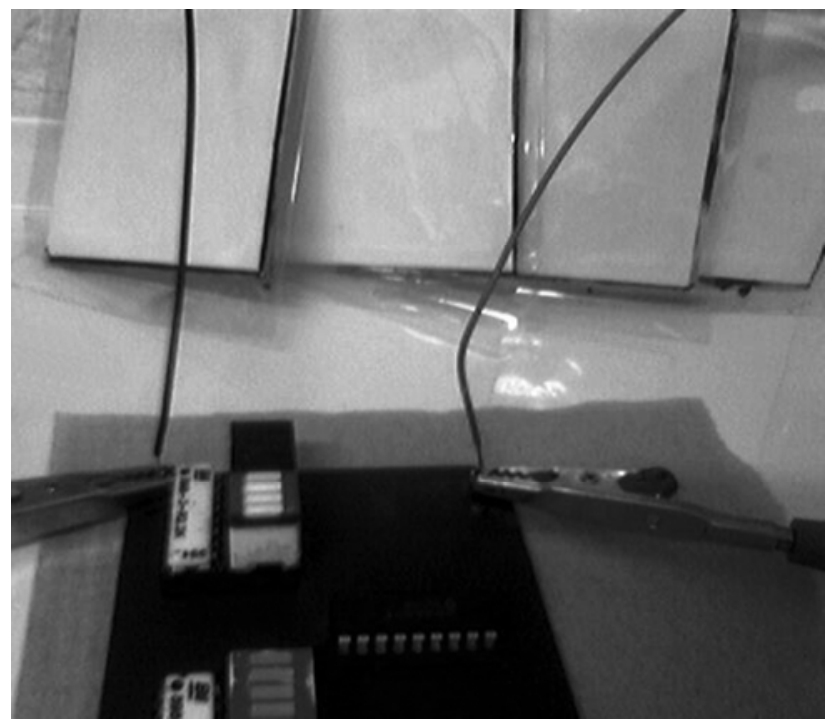

Figure 4. Lithographically printed battery- powered circuit

Ongoing development of cathodic pastes will further increase cell capacity by optimising the ratio of manganese (IV) dioxide to graphite particulates.

Development of a lithographically printable manganese (IV) dioxide / graphite ink is underway. Problems associated with high sheet resistivity are currently being investigated. A lithographically printed layer is desirable to replace the cathodic paste. Due to the thin nature of lithographically deposited ink films, it is envisaged that a cathodic ink layer will require over printing a number of times to achieve suitable ink volume. It is therefore necessary to formulate a printable ink which, while attaining a suitable sheet resistivity, will also achieve a low modulus of elasticity. This is necessary to prevent cured ink film cracking during over printing. 
This article is a version after peer-review, with revisions having been made. In terms of appearance only this might not be the same as the published article.

\section{Acknowledgments}

The authors would like to thank Narinder Bains (Rohm and Haas Electronic Materials Europe Ltd.), Peter Herdman (Arjo Wiggins Fine Papers Ltd.) and Bill MacDonald (Dupont Teijin Films Ltd.) for their assistance in support of this work. Thanks also to the IeMRC for funding the feasibility study.

\section{References}

1. Blayo, A. and Pineaux, B. 2005. Printing processes and their potential for RFID printing. In Proceedings of the 2005 Joint Conference on Smart Objects and Ambient intelligence: innovative Context-Aware Services: Usages and Technologies (Grenoble, France, October 12 - 14, 2005). ISBN:1-59593-304-2.

2.

http://www.powerpaper.com/3_technology/batteryspe cs.htm, [site visited 04/08/06].

3. Baruch Levanon. Flexible Thin Open Electrochemical Cell And Applications of Same, US Patent No. 575190. December 20, 1995.

4. Power Paper Inc. Flexible Thin Open Electrochemical Cell And Applications of Same, US Patent No. 873868. June 12, 1997.

5. VINCENT, C. A., SCROSATI, B. Modern batteries: An introduction to electrochemical power sources. 2nd edition. Arnold, U.K., 1997. 